OPEN ACCESS

Edited by:

Qingli Dong,

University of Shanghai for Science and Technology, China

Reviewed by:

Chenyang Huang,

Institute of Agricultural Resources and Regional Planning (CAAS), China

Yung-Fu Chang,

Cornell University, United States

Qi Tan,

Shanghai Academy of Agricultural

Sciences, China

*Correspondence:

Fengyun Zhao

zhaofy@kmust.edu.cn

${ }^{t}$ These authors have contributed equally to this work

Specialty section:

This article was submitted to

Food Microbiology,

a section of the journal

Frontiers in Microbiology

Received: 09 July 2018

Accepted: 20 August 2019

Published: 03 September 2019

Citation:

Chen X, Zhang Z, Liu X, Cui B, Miao W, Cheng W and Zhao F (2019)

Characteristics Analysis Reveals the Progress of Volvariella volvacea Mycelium Subculture Degeneration.

Front. Microbiol. 10:2045.

doi: 10.3389/fmicb.2019.02045

\section{Characteristics Analysis Reveals the Progress of Volvariella volvacea Mycelium Subculture Degeneration}

\author{
Xiao Chen ${ }^{1+}$, Zheng Zhang ${ }^{1,2+}$, Xiaoxia Liu $^{1}$, Bo Cui ${ }^{2}$, Wentao Miao ${ }^{3}$, Weiwei Cheng ${ }^{4}$ and \\ Fengyun Zhao ${ }^{\text {** }}$ \\ ${ }^{1}$ College of Food Science and Engineering, Gansu Agricultural University, Lanzhou, China, ${ }^{2}$ School of Food Science and \\ Technology, Qilu University of Technology, Jinan, China, ${ }^{3}$ Yucheng People's Hospital, Dezhou, China, ${ }^{4}$ College of Food and \\ Bioengineering, Henan University of Science and Technology, Luoyang, China
}

Volvariella volvacea is a typical edible Basidiomycete with a high-temperature tolerance. It has a strong fibrinolysis capability and consumes abundant agricultural wastes. In agricultural cultivation, mycelial subculturing has been adopted, leading to serious strain degeneration. In this study, continuous mycelial subculturing of the common $V$. volvacea strain V971 (original strain recorded as M0) was performed in potato dextrose agar (PDA) medium. One generation of the strain was preserved every 3 months (90 days); thus, six generations of degenerated strains (M1-M6) were obtained after 18 months of mycelial subculturing. The original and degenerated strains were preserved in sterile paraffin liquid at room temperature $\left(18-25^{\circ} \mathrm{C}\right)$. The biological traits and nutrients of $\mathrm{MO}$ and $\mathrm{M} 1-\mathrm{M} 6$ were studied. The mycelial growth rate and biomass initially increased and then decreased as the degeneration progressed, reaching minimum levels of $0.041 \pm 0.001 \mathrm{~cm} / \mathrm{h}$ and $1.82 \pm 0.25 \mathrm{~g}$, respectively, at M6. Additionally, the polysaccharide, protein, polyphenol, flavone, total amino acid, and total mineral element contents of the strains decreased continuously, reaching minimum levels of $30.12 \pm 3.12 \mathrm{~g} / 100 \mathrm{~g}, 26.42 \pm 2.1 \mathrm{~g} / 100 \mathrm{~g}, 1.08 \pm 0.05 \mathrm{~g} / 100 \mathrm{~g}, 4.23 \pm 0.21 \mathrm{~g} / 100 \mathrm{~g}$, $12.51 \mathrm{mg} / \mathrm{g}$, and $398.05 \mathrm{mg} / \mathrm{kg}$, respectively, at M6. The decolorization capability of $V$. volvacea in liquid medium supplemented with bromothymol blue and lactose reflected the degree of strain degeneration, with the capability weakening as the degeneration intensified. These results are highly significant for $V$. volvacea production. The mycelial characteristics during subculture-associated degeneration were described and provide an early identification method for $V$. volvacea's degeneration.

Keywords: Volvariella volvacea, mycelial subculture, degeneration, biological traits, nutrients, early identification

\section{INTRODUCTION}

Many edible mushroom species have been consumed as food and used as food flavoring for thousands of years. They are also an important drug source (Rai et al., 2005). However, strain degeneration restricts the development of the edible mushroom industry and decreases their biotechnological values (Magae et al., 2005). The preservation of edible mushroom strains is difficult because they are often characterized by the inability to form resistant propagules in pure 
cultures. Edible mushroom strains can only be preserved by serial transfer on agar with or without the addition of mineral oil (Voyron et al., 2009) or covered with sterile distilled water (Borman et al., 2006), or by cryopreservation and freeze-drying processes (Kitamoto et al., 2002; Palacio et al., 2017). Mycelial subculturing is a common technique used by growers. Generally, strains are subcultured every 3-4 months to maintain activity. However, the excessive subculturing of edible mushrooms may cause degeneration (Chen et al., 2017; Yin et al., 2017). Degenerated edible mushrooms are characterized by slim, fragile, and slow-growing mycelia (Magae et al., 2005; Kim et al., 2014).

Volvariella volvacea (Bull. ex. Fr.) Singer, also known as Chinese mushroom or straw mushroom, is an edible Basidiomycete that was introduced into China in the 18th century, and it was so valuable that it was often presented as a tribute to Chinese royalty (Chang, 1969, 1977). In 2010, the annual output of $V$. volvacea on the Chinese mainland was 330,000 tons, which accounted for more than $80 \%$ of the global output (Bao et al., 2013). V. volvacea is a typical edible straw mushroom with a high-temperature tolerance that preferentially grows at $30^{\circ} \mathrm{C}$. Its fruiting bodies are popular with consumers owing to their taste and high nutrient contents. Moreover, V. volvacea contains many bioactive substances with medicinal values, such as anticancer-associated polysaccharides, immunosuppressive proteins, and immunoregulation-associated agglutinins (Mathew et al., 2008; Wu et al., 2011; Sun et al., 2014). Like other edible mushrooms, degeneration limits $V$. volvacea production and development (Sermkiattipong and Charoen, 2014). In agricultural cultivation, because of $V$. volvacea's poor low-temperature resistance, it cannot be stored at low temperatures like other edible mushrooms (Guo et al., 2016). Growers prefer subculture storage for $V$. volvacea. The cultivation techniques (Ahlawat et al., 2011; Bao et al., 2013), breeding techniques (Zhao et al., 2010; Liu et al., 2011), and physiology (Diamantopoulou et al., 2016; Li et al., 2017) of V. volvacea have been investigated, but the serious consequences of strain degeneration have been overlooked. The degeneration of $V$. volvacea has been studied in China (Hu et al., 2015; Li and Wang, 2015); however, studies on the effects of mycelial subculturing on the characterizatics of edible mushrooms, specifically $V$. volvacea, have been limited.

The mycelia of edible mushrooms are rich in nutrients (Huang et al., 2006; Chiu et al., 2010) and are widely used in fermentation and medicinal fields (Mathew et al., 2008; Diamantopoulou et al., 2012; Zhang et al., 2017). Their agricultural and commercial values decrease along with the decreasing vitality of degenerated strains. However, many growers overlook the degeneration that occurs in the mycelial stage. Serious degenerative problems occur at the fruiting stage, which can result in huge economic losses (Magae et al., 2005). Thus, methods to identify degeneration early in $V$. volvacea strains should be investigated. In this study, mycelial subculturing was used to preserve $V$. volvacea strains. Moreover, the biological characteristics of, and nutrients in, degenerated mycelia were determined, and a simple method to detect $V$. volvacea strain degeneration was proposed. This study provides a theoretical basis for the early identification of degeneration in $V$. volvacea and other edible mushrooms.

\section{MATERIALS AND METHODS}

\section{Instruments, Chemicals, and Reagents}

An LGJ-12 vacuum freeze-dryer was purchased from Songyuan Huaxing Technology Develop Co., Ltd. (Beijing, China). A TU1901 spectrophotometer was purchased from Purkinje General Instrument Co., Ltd. (Beijing, China). An 835-50 automatic amino acid analyzer was purchased from Hitachi, Ltd (Tokyo, Japan), and a NoVAA400P flame atomic absorption spectrometer (F-AAS) was purchased from Analytik Jena AG Company (Jena, Germany). A FE20K electronic handheld $\mathrm{pH}$ meter was purchased from Mettler Toledo Company (Zurich, Switzerland). In the experiments, the ultrapure water used was produced from a Milli-Q integral water purification system (Millipore Corp., Billerica, MA, United States).

Bromothymol blue (BTB, cas\#: 34722-90-2), lactose (cas\#: 6342-3), glucose (cas\#: 50-99-7), rutin (cas\#: 153-18-4), and gallic acid (cas\#: 149-91-7) were purchased from Aladdin Bio-Chem Technology Co., Ltd. (Shanghai, China). The hollow cathode lamp and standards (purity $\geq 99 \%$ ) of different mineral elements were purchased from Guobiao Testing and Certification Co., Ltd. (Beijing, China). All of the reagents used in the pretreatment of mycelial samples for automatic amino acid and F-AAS analyses were of guaranteed purity.

\section{Microorganisms, Media, and Culture Conditions}

Commercial V. volvacea species (V971) in agricultural cultivation were purchased from the Edible Mushroom Research Institute, Jiangsu, China. In the experiments, all of the strains were cultured at $30^{\circ} \mathrm{C}$ if necessary. The potato dextrose broth (PDB) medium contained $200 \mathrm{~g}$ of fresh potato, $20 \mathrm{~g}$ of glucose, $1.0 \mathrm{~g}$ of $\mathrm{KH}_{2} \mathrm{PO}_{4}, 1.0 \mathrm{~g}$ of $\mathrm{MgSO}_{4} \cdot 7 \mathrm{H}_{2} \mathrm{O}$, and $1,000 \mathrm{~mL}$ of distilled water. The potato dextrose agar (PDA) medium contained $1,000 \mathrm{~mL}$ of PDB and $20 \mathrm{~g}$ of agar. Liquid medium supplemented with BTB and lactose (LBL) contained $200 \mathrm{~g}$ of potato, $20 \mathrm{~g}$ of lactose, $2 \mathrm{~g}$ of $\mathrm{NH}_{4} \mathrm{NO}_{3}, 1.5 \mathrm{~g}$ of $\mathrm{KH}_{2} \mathrm{PO}_{4}, 0.5 \mathrm{~g}$ of $\mathrm{MgSO}_{4}$, $0.06 \mathrm{~g}$ of $\mathrm{BTB}$, and $1,000 \mathrm{~mL}$ of distilled water at a $\mathrm{pH}$ of 7.0 (Magae et al., 2005).

The tip mycelia of $V$. volvacea were subcultured on PDA medium every 4 days. A $1-\mathrm{cm}^{2}$ tip mycelial agar piece was transferred into the center of a fresh PDA plate and subcultured using the same method for another 18 months. Degenerated strains were collected from the last subculturing after 3 months (90 days) and individually stored in PDA slants. The original strain was recorded as M0, and the first generation of the degenerated strain was recorded as M1. Six generations of degenerated strains were prepared (M1-M6). Sterile liquid paraffin was injected into the PDA slant tubes, and the edible mushrooms were stored at room temperature $\left(18-25^{\circ} \mathrm{C}\right)$.

For the detection of degeneration in $V$. volvacea strains, five pieces of $1-\mathrm{cm}^{2}$ tip mycelial agar were inoculated into $100 \mathrm{~mL}$ LBL medium. Cultures were shaken for 8 days in the dark $\left(30^{\circ} \mathrm{C}, 110 \mathrm{rpm}\right)$. An additional five pieces of $1-\mathrm{cm}^{2} \mathrm{PDA}$ media without $V$. volvacea were used as the control group (CK). After 
8 days, the media were centrifuged at $8,000 \times g$ for $1 \mathrm{~min}$, and the OD values of the supernatants were determined at $615 \mathrm{~nm}$ (Magae et al., 2005). The $\mathrm{pH}$ values of the LBL media were measured using an electronic handheld $\mathrm{pH}$ meter. The formula for calculating the decolorizing rate (expressed as a percentage) of LBL media was as follows:

Decolorizing rate of LBL medium (\%)

$$
=\frac{\text { ODck }- \text { ODsample }}{\text { ODck }} \times 100 \%
$$

\section{Mycelial Growth Rate Assay}

The mycelial growth rate was determined using the method of Diamantopoulou et al. (2012) with slight modifications. Briefly, the $V$. volvacea colonies radii were measured at $48 \mathrm{~h}$ after each inoculation. The growth rate of each generation of strains indicated the ratio of total $V$. volvacea strain colony radius at $90 \mathrm{~d}$ to 23 (the $V$. volvacea colony radius was measured 23 times over the 90-days period). The formula for the growth rate of each generation was as follows:

Growth rate of mycelia $(\mathrm{cm} / \mathrm{h})$

$$
=\frac{\text { the total } V . \text { volvacea colony radius in } 90 \text { days }}{23 \times 48 \mathrm{~h}}
$$

\section{Mycelial Biomass Assay}

The mycelial biomass of each generation of $V$. volvacea was determined using the method reported by Diamantopoulou et al. (2012) with slight modifications. Briefly, V. volvacea strains were activated twice on PDA medium, and five pieces of $1-\mathrm{cm}^{2}$ tip mycelium agar were cultured in $100 \mathrm{~mL}$ of $\mathrm{PDB}$ medium for 8 days at $30^{\circ} \mathrm{C}$. After the culture solution and agar pieces were removed, the mycelia were washed with deionized double-distilled water $\left(\mathrm{ddH}_{2} \mathrm{O}\right)$ three times. The mycelial biomass' concentration was determined from the dry weight. Fungal mycelia were harvested from the vacuum freezedryer. Afterward, the mycelia were weighed, and each sample was tested 10 times.

\section{Mycelial Nutrient Assay}

Vacuum freeze-dried mycelia $(0.5 \mathrm{~g})$ were pulverized and passed through a 60 -mesh sieve. They were then carefully collected and placed in $10 \mathrm{~mL} 60 \%$ methanol solution (Rajauria et al., 2010). The mixture was processed at $100^{\circ} \mathrm{C}$ for $15 \mathrm{~min}$ and centrifuged at $5,000 \times g$ for $15 \mathrm{~min}$ at $4^{\circ} \mathrm{C}$ to obtain the supernatant. Residues were extracted twice using the same method, and the supernatants were processed three times and mixed, to obtain the crude nutrient extract. The total polysaccharide content was determined using the phenolsulfuric acid method. The standard curve was prepared with glucose as the standard, and the absorbance values of samples were detected at $490 \mathrm{~nm}$ (Zhou et al., 2014). The total flavone content was determined using $\mathrm{NaNO}_{2}-\mathrm{Al}\left(\mathrm{NO}_{3}\right)_{3}-\mathrm{NaOH}$ colorimetry. The standard curve was prepared with rutin as the standard, and the absorbance values of samples were detected at $510 \mathrm{~nm}$ (Ozsoy et al., 2008). The total polyphenol content was determined using the Folin-Ciocalteu reagent method. The standard curve was prepared with gallic acid as the standard, and the absorbance values of samples were detected at $760 \mathrm{~nm}$ (Mihai et al., 2012). The total protein content was tested using the Kjeldahl method. As described in the method, nitric organic substances were converted into ammonium salts, and ammonia was distilled to the standard acid solution. The results are presented in mg per $1 \mathrm{~g}$ of vacuum-freeze dried mycelia (Barbano et al., 1991).

A certain measured amount of vacuum freeze-dried mycelia was pulverized, passed through a 60-mesh sieve and placed into a hydrolysis tube. Next, $6 \mathrm{~N} \mathrm{HCl}(10 \mathrm{~mL})$ was added, and the tube was vacuum-packed and sealed. The mycelia were hydrolyzed at $110^{\circ} \mathrm{C}$ for $24 \mathrm{~h}$. Subsequently, they were evaporated to dryness and diluted to the appropriate concentration. They were used to determine the contents of various amino acids in mycelia using an automatic amino acid analyzer. Test conditions for the analyzer were set as follows: chromatographic column diameter, $2.6 \times 150 \mathrm{~mm}$; ion exchange resin, Hitachi-2619 type; flow rate of buffer solution, $0.225 \mathrm{~mL} / \mathrm{min}$; flow rate of ninhydrin, $0.3 \mathrm{~mL} / \mathrm{min}$; pumping pressure of buffer solution, $80-120 \mathrm{~kg} / \mathrm{cm}^{2}$; pumping pressure of ninhydrin, $15-35 \mathrm{~kg} / \mathrm{cm}^{2}$; column temperature, $53^{\circ} \mathrm{C}$; sample feeding rate, $50 \mu \mathrm{L}$; standard sample feeding rate, $3 \mathrm{nmol} / 50 \mu \mathrm{L}$; and nitrogen pressure, $0.28 \mathrm{~kg} / \mathrm{cm}^{2}$.

Trace elements ( $\mathrm{Ca}, \mathrm{Cu}, \mathrm{Fe}, \mathrm{K}, \mathrm{Mg}, \mathrm{Mn}, \mathrm{Na}$, and $\mathrm{Zn}$ ) were determined in each vacuum freeze-dried mycelial sample using F-AAS. The pretreatment of samples was based on the method reported by $\mathrm{Li}$ et al. (2011). Laboratory glassware was kept overnight in a $10 \% \quad v / v \mathrm{HNO}_{3}$ solution and then rinsed with deionized $\mathrm{ddH}_{2} \mathrm{O}$. In total, $1 \mathrm{~g}$ of powdered sample was weighed into a $100-\mathrm{mL}$ glass beaker. Then, $10 \mathrm{~mL}$ of $\mathrm{HNO}_{3}$ and $2 \mathrm{~mL}$ of $\mathrm{H}_{2} \mathrm{O}_{2}$ were added to the sample. The mixture was digested on a hot plate at low temperature for $2 \mathrm{~h}$, and afterward, $15 \mathrm{~mL}$ of deionized water was added. Solutions were precisely transferred to 100$\mathrm{mL}$ volumetric flasks and filled to the full volume with deionized $\mathrm{ddH}_{2} \mathrm{O}$. The optical parameters of F-AAS used for mineral element determination experiments are shown in Supplementary Table S1.

\section{Statistical Analyses}

All of the samples were analyzed in triplicate, unless otherwise specified. The results were expressed as means \pm standard deviations (SDs) and subjected to an analysis of variance. The means were separated using Duncan's multiple range test with the aid of SPSS version 22.0 software (SPSS Inc., United States). A heatmap was created using $\mathrm{R}$ software (v. 3.1.0). ${ }^{1}$ Variables included the amino acid and mineral element data, which were subsequently tagged as irrational values after the log-normalization generated in the R software.

\footnotetext{
${ }^{1}$ http://cran.cnr.berkeley.edu/
} 


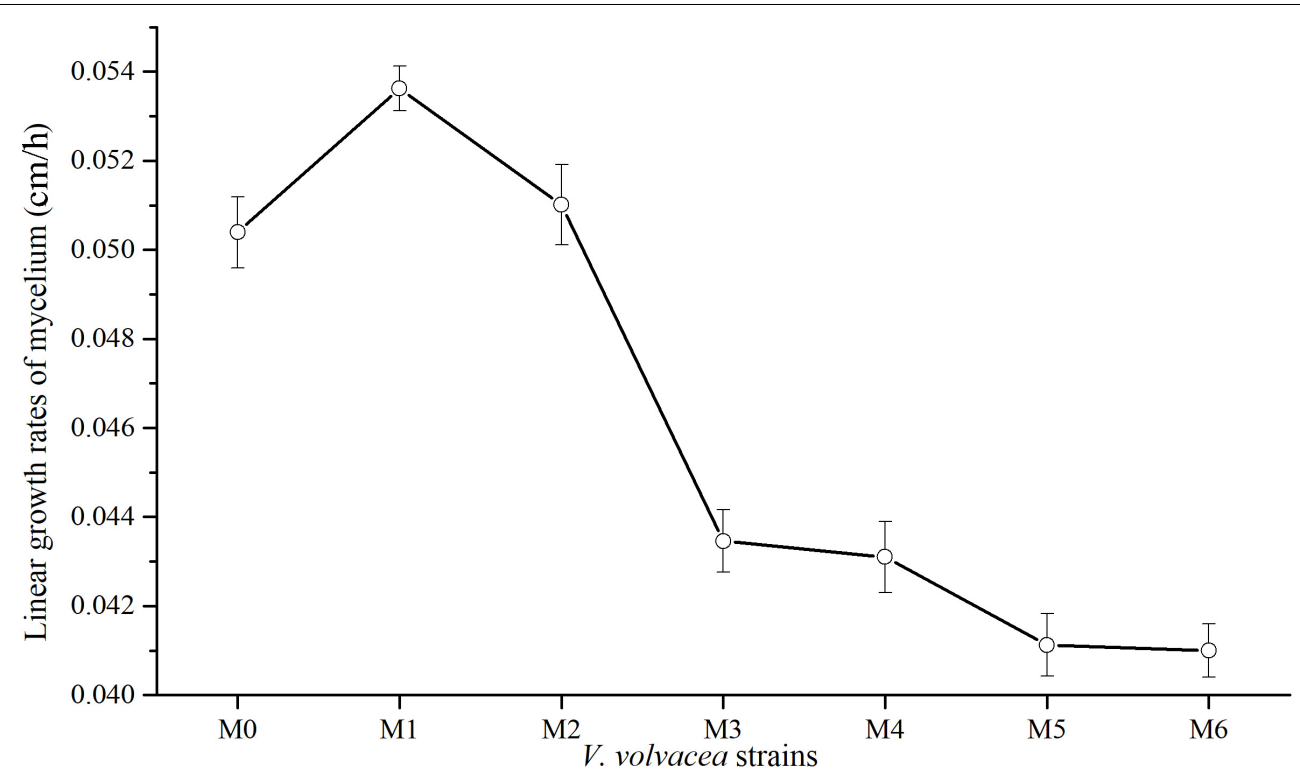

FIGURE 1 | Mycelial growth rates of $V$. volvacea strains. Values represent the means \pm SDs of triplicate samples.

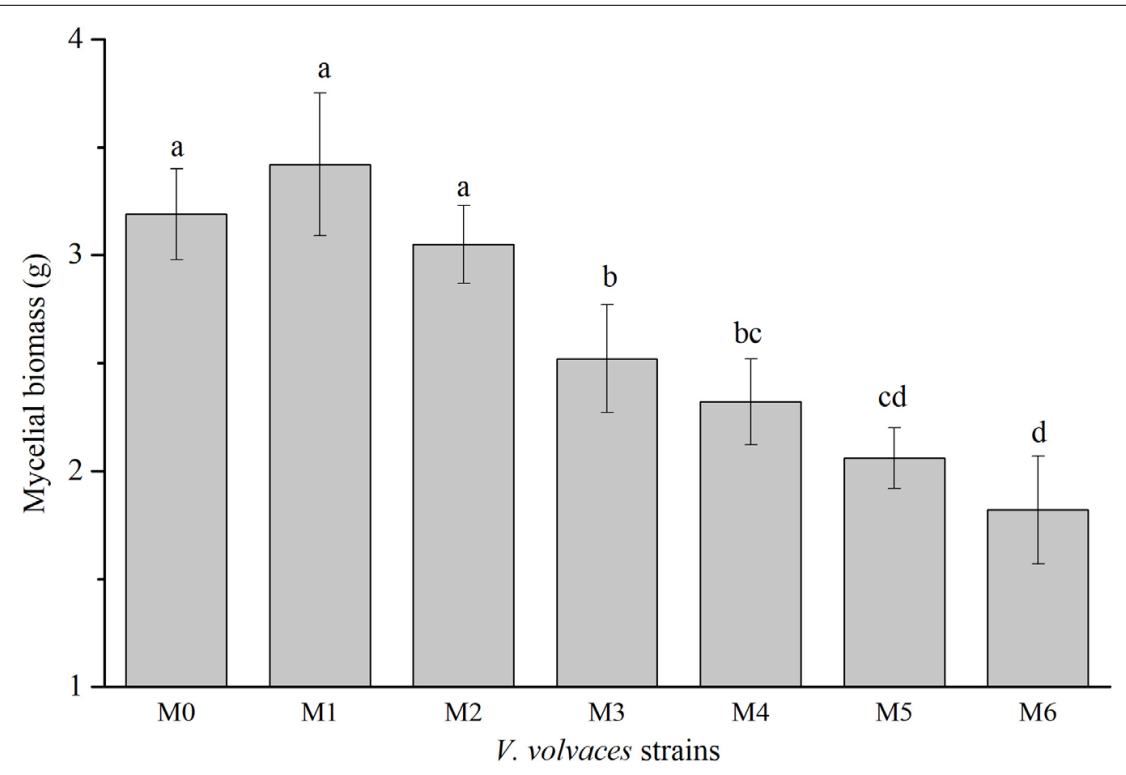

FIGURE 2 | Dry mycelial biomasses of $V$. volvacea strains. Values represent the means \pm SDs of triplicate samples. Different letters were significantly different $(P<0.05)$.

\section{RESULTS}

\section{Mycelial Growth Rates of Different V. volvacea Strains}

Subcultures of $V$. volvacea mycelia were passaged for 18 months, and the kinetic behaviors of the tested $V$. volvacea strains were assessed on PDA medium. The obtained radial growth rates of M0-M6 were determined (Figure 1). The growth rates of $V$. volvacea mycelia significantly changed during the subculturing, reaching a maximum at M1 $(0.0534 \pm 0.001 \mathrm{~cm} / \mathrm{h})$ and sharply declining thereafter until M6 $(0.041 \pm 0.001 \mathrm{~cm} / \mathrm{h})$. The growth rates of the mycelia tended to be stable at M3 and reached their minimum values at M6, showing significant differences compared with M0 $(0.0503 \pm 0.001 \mathrm{~cm} / \mathrm{h} ; P<0.05)$.

\section{Mycelial Biomasses of Different V. volvacea Strains}

Subcultures of $V$. volvacea mycelia were passaged for 18 months on PDA medium, and mycelial biomasses of M0-M6 were determined (Figure 2). The mycelial biomasses of M0, M1, and 


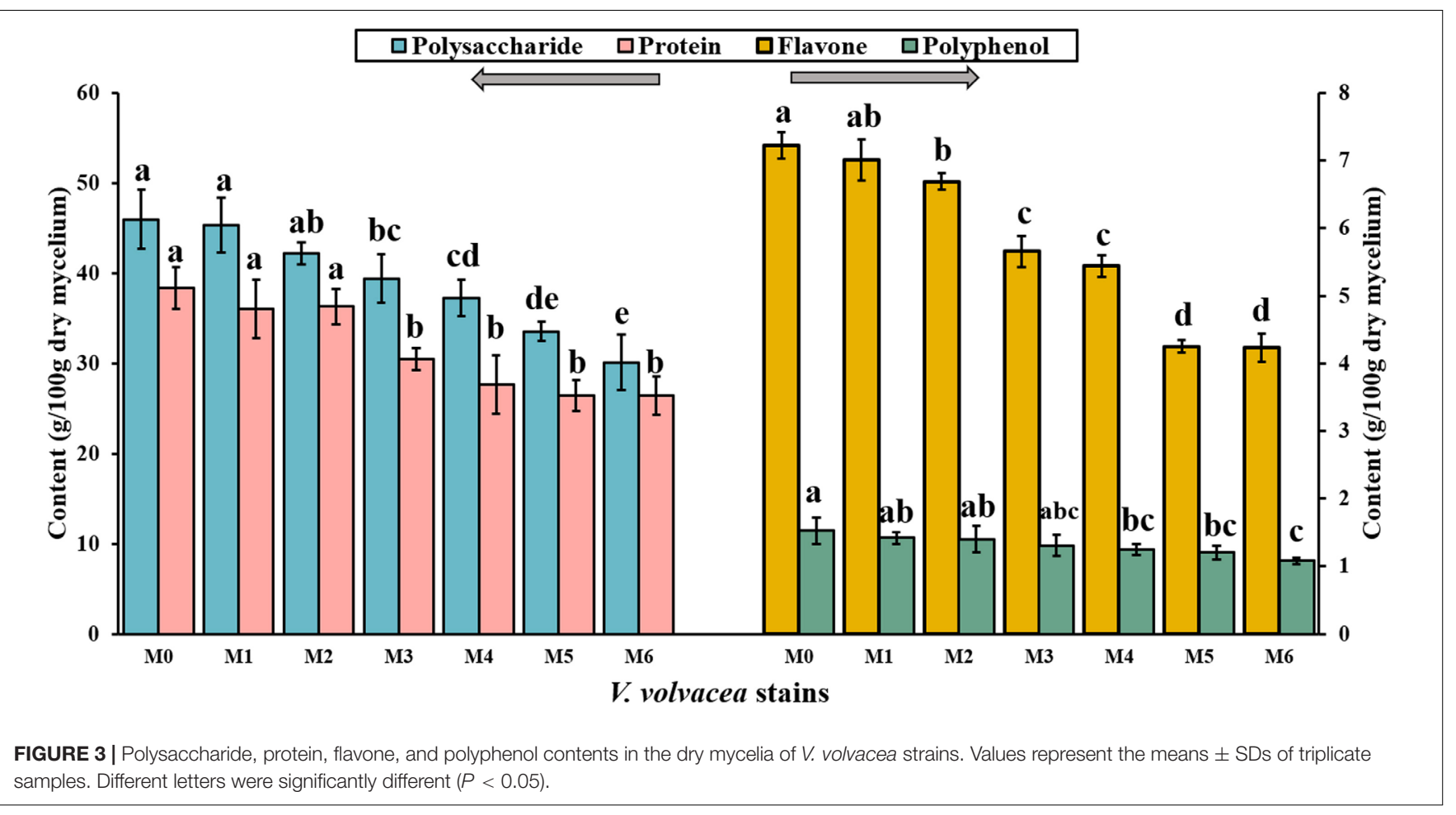

$\mathrm{M} 2$ were $3.19 \pm 0.21 \mathrm{~g}, 3.42 \pm 0.33 \mathrm{~g}$, and $2.62 \pm 0.13 \mathrm{~g}$, respectively, and there were no significant differences among the three groups $(P>0.05)$. However, the mycelial biomasses of M0, M1, and M2 were significantly different from those of other generations (M3-M6; $P<0.05$ ). The maximum mycelial biomasses occurred at M1, while the minimum mycelial biomasses were achieved at M6 (1.82 $\pm 0.25 \mathrm{~g})$.

\section{Polysaccharide, Protein, Flavone, and Polyphenol Contents in Different V. volvacea Strains}

Subcultures of $V$. volvacea mycelia were passaged for 18 months on PDA medium, and the contents of polysaccharide, protein, flavone, and polyphenol compounds in M0-M6 were determined (Figure 3). M0 had the greatest nutrient values (polysaccharide, $46.01 \pm 3.3 \mathrm{~g} / 100 \mathrm{~g}$; protein, $38.36 \pm 2.32 \mathrm{~g} / 100 \mathrm{~g}$; flavone, $7.22 \pm 0.2 \mathrm{~g} / 100 \mathrm{~g}$; and polyphenol, $1.53 \pm 0.19 \mathrm{~g} / 100 \mathrm{~g})$. With the continuation of $V$. volvacea mycelial subculturing, the nutrient contents of the degenerated strains gradually decreased. The polysaccharide, protein, flavone, and polyphenol contents deceased to $30.12 \pm 3.12 \mathrm{~g} / 100 \mathrm{~g}, 26.42 \pm 2.1 \mathrm{~g} / 100 \mathrm{~g}$, $4.23 \pm 0.21 \mathrm{~g} / 100 \mathrm{~g}$, and $1.08 \pm 0.05 \mathrm{~g} / 100 \mathrm{~g}$, respectively, at M6, which were significantly different compared with their values at M0 $(P<0.05)$.

\section{Changes in Amino Acid and Mineral Element Contents in Different $V$. volvacea Strains}

Subcultures of $V$. volvacea mycelia were passaged for 18 months on PDA medium. The amino acid and mineral element contents in M0-M6 were determined and are shown in Supplementary Tables S2, S3, respectively. V. volvacea contained abundant and various amino acids and mineral elements. The total amino acid and mineral element contents in M0 were $12.51 \mathrm{mg} / \mathrm{g}$ and $398.05 \mathrm{mg} / \mathrm{kg}$, respectively. However, they decreased continuously as the subculturing continued and reached $7.18 \mathrm{mg} / \mathrm{g}$ and $332.11 \mathrm{mg} / \mathrm{kg}$, respectively, in M6. The amino acid and mineral element data were normalized and expressed as heatmaps (Figure 4). The glutamic acid, histidine, tyrosine, and threonine contents in M6 were significantly lower than those in M0 $(P<0.001)$. Additionally, the cysteine, glycine, phenylalanine, and $\mathrm{Zn}$ contents in M6 were significantly lower than those in M0 $(P<0.01)$. The greatest amino acid and mineral contents were found in M0. Although the contents decreased to some extent as the subculturing continued, not all of the contents had positive correlations with subculture time (e.g., aspartic acid, serine, lysine, and K). The arginine and tryptophan contents were not determined in this study (Supplementary Table S2).

\section{LBL Medium for Detecting the Degeneration of $V$. volvacea Strains}

The decolorization capabilities of M0-M6 in LBL media were evaluated. Changes in visual color, decolorization ratios, and $\mathrm{pH}$ values were determined, and the results are shown in Figures 5A-C, respectively. As the degeneration of $V$. volvacea strains progressed, the decolorizing rate of the LBL media gradually weakened, and the color changed from orange (M0) to dark blue (M6, which was similar to CK) (Figure 5A). The decolorization ratios of M0 and M6 LBL media were $97.94 \% \pm 0.42 \%$ and $2.84 \% \pm 1.7 \%$, respectively, showing a 


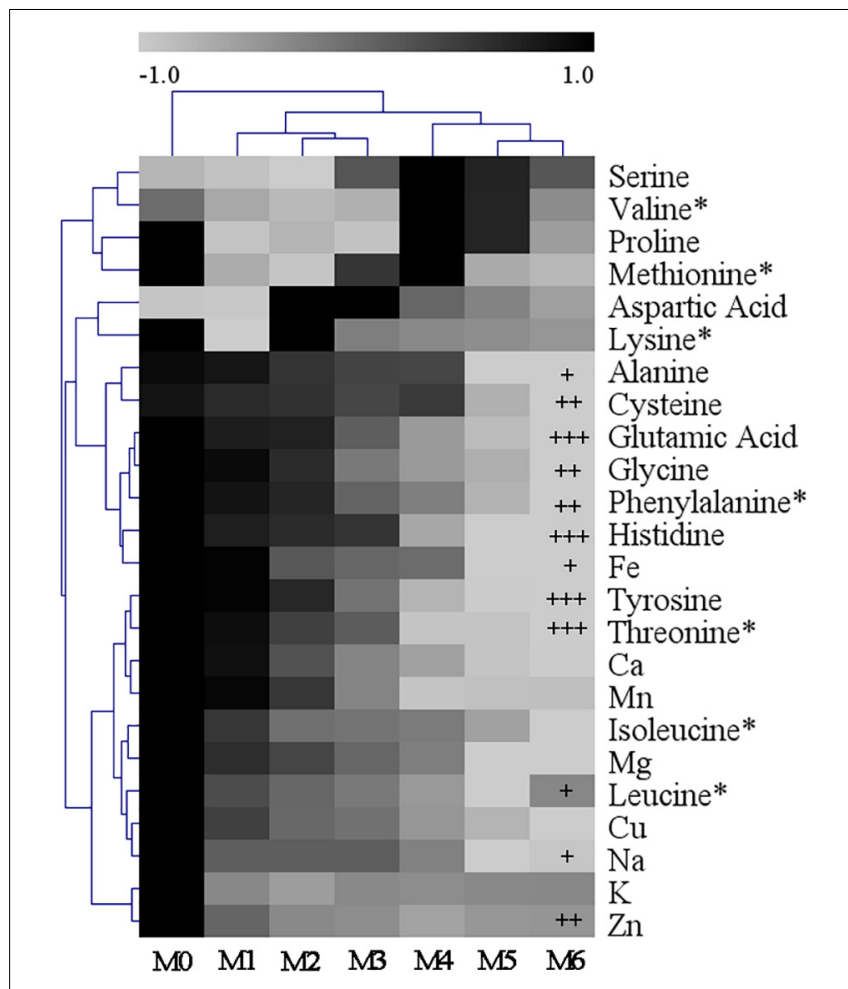

FIGURE 4 | Heatmap showing the normalized content values of amino acids and mineral elements among the different $V$. volvacea strains. The normalized content values are depicted visually from black to gray; black represents the greatest value and gray the lowest value. The dendrogram distances represent the amino acids and mineral elements (left) based on their content values in the strains (top). $T$-tests were used to identify the differences between $\mathrm{M0}$ and M6. +: $P<0.05 ;++: P<0.01$; and +++: $P<0.001$. *: essential amino acid.

significant difference $(P<0.05)$ (Figure 5B). The $\mathrm{pH}$ values of M0, M6, and CK LBL media were $4.34 \pm 0.01,6.92 \pm 0.03$, and $7.00 \pm 0.01$, respectively. The $\mathrm{pH}$ values of M0 and M6 (or CK) LBL media were significantly different $(P<0.05)$, while the CK and M6 LBL media values showed no significant difference $(P>0.05$; Figure 5C). In addition, positive correlations between $\mathrm{pH}$ and $\mathrm{OD}$ values were observed in LBL media inoculated with $V$. volvacea strains (coefficient of determination $R^{2}=0.902$; Figure 5D), indicating the lower decolorization capabilities of the degenerated $V$. volvacea strains in LBL media.

\section{DISCUSSION}

Liquid paraffin can be used to store most fungi for a long time periods, even decades. After residual paraffin is removed from mycelia, normal strain growth can be recovered (Little and Gordon, 1967). Because the liquid paraffinbased storage techniques of edible mushroom strains require complicated operational environments and skillful technologies, growers often adopt simple subculturing processes, which cause continuous degeneration and great losses. Magae and Hayashi (1999) discovered two dsRNA elements and viral-like particles in the mycelia of Flammulina velutipes derived from a spontaneously brown-colored fruit body. They were not detected in the normal strains in fruiting-impaired degenerative isolates. Kim et al. (2014) reported that the symptoms of degenerated F. velutipes strains include slow vegetative growth, a compact mycelial mat, and few, or even no, fruiting bodies. Yin et al. (2017) artificially cultured the entomopathogenic mushroom Cordyceps militaris for six generations and observed changes during fruiting-body growth. The subcultured C. militaris strains began degenerating in the third generation, with incomplete fruiting-body growth beginning in the fourth generation. In the entomogenous fungi Metarhizium anisopliae, strains showed a reductions in, or the infertility of, spores after degeneration, accompanied with the development of villiform mycelia and changes in mitochondrial DNA (Wang et al., 2005). In this study, the symptoms of degenerated V. volvacea strains included slow mycelial growth rates and low mycelial biomasses, which are similar to the findings of a previous study (Sun et al., 2017). Additionally, the cultivation experiment revealed that, compared with $\mathrm{M} 0$, the biological efficiencies of M1-M3 significantly decreased, and the production cycles were significantly prolonged. The M4-M6 obtained by mycelial subculturing for 12-18 months lack the capabilities to produce fruiting bodies (unpublished data). These degradation-related characteristics are basically consistent with those of other edible mushrooms (Sun et al., 2017). The degeneration of edible mushrooms occurs frequently during agricultural cultivation. However, limited studies on degeneration resulting from the mycelial subculturing of edible mushrooms, especially $V$. volvacea, have been performed.

Basidiomycete' hyphae grow continuously through the divisions of tip cells (Badalyan et al., 2004). The tip mycelia of Basidiomycetes have strong activity levels, and in the ectomycorrhizal basidiomycete Amanita muscaria, they are linked to the expression and transcriptional level of an $\alpha$-tubulin gene. They also have a direct impact on the mycelial growth rate (Tarkka et al., 2006). In addition, Li et al. (2003) cultured tip mycelia of Sclerotinia sclerotiorum (vegetable fungi) on a PDA medium and found that the tip mycelia were highly stable. The tip mycelia reached a growth state and could generate a strong toxicity. Thus, the tip mycelia of $V$. volvacea were chosen for subculturing in this study. The mycelial growth rate can determine the growth-related vitality of $V$. volvacea mycelia. The greater the growth rate, the stronger the mycelial activity level (Mata and Savoie, 1998; Ahlawat et al., 2008). In this study, the growth rates of degenerated strains declined continuously (Figure 1), which might be the consequences of the reduced activity levels of $V$. volvacea. The mycelial biomasses of edible mushrooms can reflect their outputs, to some extent. Generally, the culture media used for $V$. volvacea were optimized based on mycelial biomass (Diamantopoulou et al., 2016). In this study, there was no significant difference in the mycelial biomass between M1 and M0 $(P>0.05)$, but there were significant differences in the mycelial biomasses between M2-M6 and M0 $(P<0.05)$ (Figure 2). Thus, the mycelial biomasses of degenerated strains decreased continuously as the subculturing continued, which might result in unsatisfying, and even a lack of, output from degenerated strains (Kim et al., 2014; 


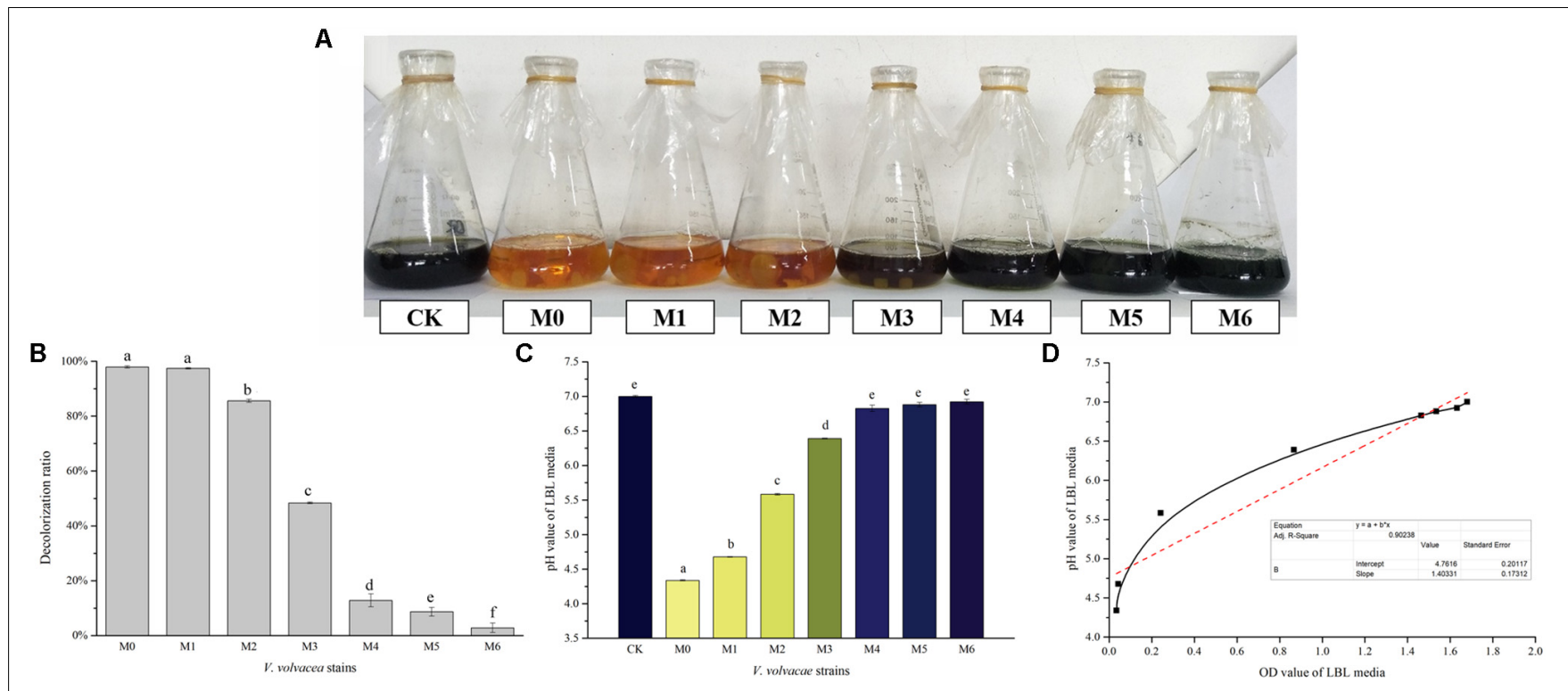

FIGURE 5 | Characterization of LBL media inoculated with $V$. volvacea strains. (A) Visual colors of the LBL $V$. volvacea mycelial fermentation media. (B) Decolorization ratios of the LBL media. (C) $\mathrm{pH}$ values of the LBL media. (D) Correlation analyses between $\mathrm{pH}$ and OD values of the LBL $V$. volvacea mycelial fermentation media. Values represent the means \pm SDs of triplicate samples. Different letters were significantly different $(P<0.05)$.

Chen et al., 2017; Yin et al., 2017). Moreover, we discovered a similar trend between the mycelial growth rate and mycelial biomass as the subculturing continued. Therefore, the mycelial growth rate and mycelial biomass might be positively correlated.

Volvariella volvacea is rich in nutrients (Wang et al., 2009). Changes in nutrients are an important indication of $V$. volvacea degeneration. They not only represent the commercial and agricultural values of $V$. volvacea but also reflect the strength of internal biochemical reactions. In this experiment, the nutrients of M0 and M1-M6 were determined. The polysaccharide, protein, flavone, and polyphenol contents decreased continuously as the subculturing continued (Figure 3 ), and the effects of the subculturing were greatest on glutamic acid, histidine, tyrosine, and threonine levels (Figure 4). However, this trend was not observed for all nutrients, such as aspartic acid, serine, $\mathrm{K}$, and Fe (Figure 4). Strain degeneration results in huge losses to the growers and presents a great challenge to breeders.

Edible mushrooms degrade cellulose, lignin, and other macromolecules in the medium into micromolecules for growth and development, which requires mutual conversions among sugars, proteins, amino acids, and other substances (Drewnowska and Falandysz, 2015). Valine and serine have strong inhibitory effects on the growth of mycelia (Kalac, 2009), and similar results were obtained here, with the valine and serine contents increasing from M1 to M4 (Figure 4). Alanine can effectively improve the absorption of nitrogen by mycelia and promote the formation of primordia and fruiting bodies (Meng et al., 2019). In this study, alanine showed a decreasing trend from M1 to M6, which may explain why $V$. volvacea could not produce fruiting bodies after 12 months of continuous mycelial subculturing. Mineral nutritional elements are the necessary activators or active agents in many enzyme reactions in $V$. volvacea. More than 50-70\% of enzymes need to be activated by mineral elements to catalyze related biochemical reactions (Santos et al., 2015). Cu is located in the active site of laccase, which is helpful for xylogen degradation (Liu et al., 2015), and laccase in V. volvacea is correlated with fruiting body formation (Chen et al., 2003). Ca may contribute to the aggregative effect of enriched nutrient elements, and strains enriched with $\mathrm{Ca}$ may promote the carboxymethyl cellulase activity (Maijala et al., 1991). Zn is an essential element for the synthesis of tryptophan. When edible fungi lack $\mathrm{Zn}$, the activity levels of superoxide dismutase in cells decreases (Bellomo et al., 2014). The fat content of a strain enriched with Fe significantly increase (Jedidi et al., 2017). In this study, the contents of eight mineral elements in the mycelia of $V$. volvacea gradually decreased from M1 to M6, which probably lead to the decreased activities of cellulase and other enzymes, contributing to the further degradation of $V$. volvacea.

In Japan, in 2005, Magae et al. (2005) identified the degeneration of $F$. velutipes based on color changes in the LBL medium. Degenerated strains have poor decolorizing capabilities in the LBL medium. Here, we reported that the decolorizing capability of the $V$. volvacea strains in LBL medium weakened as they degenerated (Figures 5A,B). Although this identification method is simple and easy-to-operate, the mechanism remains unknown. BTB in LBL media, a textile dye derivative often deployed as a $\mathrm{pH}$ indicator, which turns yellow in an acid environment, has been used as an indicator of free radical pollutants (Hoag et al., 2009). Hoag et al. (2009) demonstrated a decrease in the rate of BTB degradation as the amounts of free radicals increased. In this experiment, the changes in active substances (e.g., polyphenol, flavone, and mineral elements) in $V$. volvacea strains during degeneration were investigated (Figures 3, 4). The active substances could eliminate reactive 
oxygen species and inhibit lipid peroxidation (Ebrahimzadeh et al., 2010). As the degeneration progresses, the radicalscavenging capability decreases because the levels of these active components are reduced, which may lead to the lack of a significant color change in the media of degenerated strains. Moreover, during fermentation, organic acids, amino acids, and $\mathrm{CO}_{2}$ are produced by metabolic strains. These substances have high solubility levels in aqueous solutions and produce free hydrogen ions in water. In a medium with a low buffering capacity, the reaction results in a severe drop in $\mathrm{pH}$ (Figure 5C), which further affects the color of the LBL medium (Shen et al., 2004; Zhao et al., 2015). As the degeneration intensifies, the decolorizing rate of the LBL medium gradually decreased as the $\mathrm{pH}$ value of the fermentation liquid increased. In addition, the color changed from orange (M0) to brown (M3), and then to dark blue in M4-M6 (Figures 5A,D), which was consistent with cultivation experiments in which only M0-M3 could produce fruiting bodies (unpublished data). The experiment clearly showed that when the LBL medium turned dark blue, $V$. volvacea had degraded to the point where it was no longer suitable for production. This provides a method for the early identification of $V$. volvacea degeneration, which will help avoid economic losses caused by blind cultivation. Overall, the LBL medium assay, a simple colorimetric method, was highly efficient in identifying degenerated $V$. volvacea strains with poor nutrient levels and low decolorizing capabilities.

\section{CONCLUSION}

As a typical edible straw mushroom with a high-temperature tolerance, $V$. volvacea cannot be stored under low temperature. Mycelial subculturing facilitates the degeneration of $V$. volvacea

\section{REFERENCES}

Ahlawat, O. P., Gupta, P., Dhar, B. L., Sagar, T. G., Rajendranath, R., and Rathnam, K. (2008). Profile of the extracellular lignocellulolytic enzymes activities as a tool to select the promising strains of Volvariella volvacea (Bull. ex Fr.) sing. Indian J. Microbiol. 48, 389-396. doi: 10.1007/s12088-008-0015-4

Ahlawat, O. P., Singh, R., and Kumar, S. (2011). Evaluation of Volvariella volvacea strains for yield and diseases/insect-pests resistance using composted substrate of paddy straw and cotton mill wastes. Indian J. Microbiol. 51, 200-205. doi: 10.1007/s12088-011-0126-1

Badalyan, S. M., Polak, E., Hermann, R., Aebi, M., and Kües, U. (2004). Role of peg formation in clamp cell fusion of homobasidiomycete fungi. J. Basic. Microb. 44, 167-177. doi: 10.1002/jobm.200310361

Bao, D., Gong, M., Zheng, H., Chen, M., Zhang, L., Wang, H., et al. (2013). Sequencing and comparative analysis of the straw mushroom (Volvariella volvacea) genome. Plos One 8:e58294. doi: 10.1371/journal.pone.00 58294

Barbano, D. M., Lynch, J. M., and Fleming, J. R. (1991). Direct determination of true protein content of milk by kjeldahl analysis: collaborative study. J. - Assoc. Off. Anal. Chem. 74, 281-288.

Bellomo, E., Hogstrand, C., and Maret, W. (2014). Redox and zinc signalling pathways converging on protein tyrosine phosphatases. Free Radic. Biol. Med. 75:S9. doi: 10.1016/j.freeradbiomed.2014.10.851

Borman, A. M., Szekely, A., Campbell, C. K., and Johnson, E. M. (2006). Evaluation of the viability of pathogenic filamentous fungi after prolonged storage in strains. In this study, the original generation (M0) and degenerated strains (M1-M6) of $V$. volvacea were acquired by subculturing mycelia for 18 months. The biological traits and nutrient contents of these strains were determined. As the subculturing continued, the growth rates and biomasses of $V$. volvacea mycelia initially increased and then decreased. The total polysaccharide, protein, polyphenol, flavone, amino acid, and mineral contents gradually deceased. The LBL medium was used to identify degenerated $V$. volvacea strains. The decolorizing capability of degenerated $V$. volvacea strains in LBL medium was weakened. This study discusses the degeneration of $V$. volvacea strains during subculturing and offers a feasible rapid identification method for $V$. volvacea strain degeneration.

\section{AUTHOR CONTRIBUTIONS}

$\mathrm{ZZ}$ and $\mathrm{XC}$ wrote the manuscript. $\mathrm{ZZ}$ and $\mathrm{FZ}$ designed the research. $\mathrm{ZZ}$ and $\mathrm{XL}$ performed the research. $\mathrm{BC}$ and $\mathrm{WM}$ provided experimental materials and equipment. XC and WC analyzed the data.

\section{FUNDING}

This research was financially supported by the National Natural Science Foundation of China (Grant No: 31560576).

\section{SUPPLEMENTARY MATERIAL}

The Supplementary Material for this article can be found online at: https://www.frontiersin.org/articles/10.3389/fmicb. 2019.02045/full\#supplementary-material

sterile water and review of recent published studies on storage methods. Mycopathologia 161, 361-368. doi: 10.1007/s11046-006-0023-z

Chang, S. T. (1969). A cytological study of spore germination of Volvariella volvacea. Botanical. Mag. Tokyo 82, 102-109. doi: 10.15281/jplantres1887.82. 102

Chang, S. T. (1977). The origin and early development of straw mushroom cultivation. Econ. Bot. 31, 374-376. doi: 10.1007/bf02866890

Chen, S., Ma, D., Ge, W., and Buswell, J. A. (2003). Induction of laccase activity in the edible straw mushroom, Volvariella volvacea. FEMS Microbiol. Lett. 218, 143-148. doi: 10.1016/s0378-1097(02)01131-x

Chen, A., Wang, Y., Shao, Y., and Huang, B. (2017). A novel technique for rejuvenation of degenerated caterpillar medicinal mushroom, Cordyceps militaris (Ascomycetes), a valued traditional chinese medicine. Int. J. Med. Mushrooms 19, 87-91. doi: 10.1615/IntJMedMushrooms.v19.i1.90

Chiu, K. W., Lam, A. H. W., and Pang, P. K. T. (2010). Cardiovascular active substances from the straw mushroom, Volvariella volvacea. Phytother. Res. 9, 93-99. doi: 10.1002/ptr.2650090203

Diamantopoulou, P., Papanikolaou, S., Aggelis, G., and Philippoussis, A. (2016). Adaptation of Volvariella volvacea metabolism in high carbon to nitrogen ratio media. Food. Chem. 196, 272-280. doi: 10.1016/j.foodchem.2015. 09.027

Diamantopoulou, P., Papanikolaou, S., Katsarou, E., Komaitis, M., Aggelis, G., and Philippoussis, A. (2012). Mushroom polysaccharides and lipids synthesized in liquid agitated and static cultures. Part II: study of Volvariella volvacea. Appl. Biochem. Biotech. 167, 1890-1906. doi: 10.1007/s12010-012-9714-8 
Drewnowska, M., and Falandysz, J. (2015). Investigation on mineral composition and accumulation by popular edible mushroom common chanterelle (Cantharellus cibarius). Ecotoxicol. Environ. Saf. 113, 9-17. doi: 10.1016/j. ecoenv.2014.11.028

Ebrahimzadeh, M. A., Nabavi, S. M., Nabavi, S. F., Eslami, S., and Bekhradnia, A. R. (2010). Mineral elements and antioxidant activity of three locally edible and medicinal plants in Iran. Asian. J. Chem. 22, 6257-6266.

Guo, X. Y., Lin, S. L., Guo, L. Q., Lin, J. F., and Ye, Z. W. (2016). Heterologous expression of the multi-functional cellulase gene $(\mathrm{mfc})$ from the mollusc Ampullaria crossean, in Volvariella volvacea. J. Pomol. Hortic. Sci. 91, 325-331. doi: 10.1080/14620316.2016.1160541

Hoag, G. E., Collins, J. B., Holcomb, J. L., Hoag, J. R., Nadagouda, M. N., and Varma, R. S. (2009). Degradation of bromothymol blue by 'greener' nanoscale zero-valent iron synthesized using tea polyphenols. J. Mater. Chem. 19, 8671-8677.

Hu, F., Fu, J., Wu, X., Zhang, Y., Yan, J., and Xie, B. (2015). Relativity between asymmetric nuclear division and strain degeneration in Volvariella volvacea. J. S. Agric. 46, 466-470.

Huang, S. J., Tsai, S. Y., Lee, Y. L., and Mau, J. L. (2006). Nonvolatile taste components of fruit bodies and mycelia of Cordyceps militaris. LWT Food Sci. Technol. 39, 577-583. doi: 10.1016/j.lwt.2005.05.002

Jedidi, I. K., Ayoub, I. K., Philippe, T., and Bouzouita, N. (2017). Chemical composition and nutritional value of three Tunisian wild edible mushrooms. J. Food Meas. Charact. 11, 2069-2075. doi: 10.1007/s11694-017-9590-6

Kalac, P. (2009). Chemical composition and nutritional value of European species of wild growing mushrooms: a review. Food Chem. 113, 9-16. doi: 10.1016/j. foodchem.2008.07.077

Kim, S. Y., Kim, K. H., Im, C. H., Ali, A., Lee, C. Y., Kong, W. S., et al. (2014). Identification of degenerate nuclei and development of a SCAR marker for Flammulina velutipes. Plos One 9:e107207. doi: 10.1371/journal.pone.01 07207

Kitamoto, Y., Suzuki, A., Shimada, S., and Yamanaka, K. (2002). A new method for the preservation of fungus stock cultures by deep-freezing. Mycoscience 43, 143-149. doi: 10.1007/s102670200021

Li, D., and Wang, J. (2015). Screening of molecular markers associated with degeneration of Volvariella volvacea strains. J. Northwest A F Univ. 43, 195-201.

Li, G., Huang, H., Laroche, A., and Acharya, S. (2003). Occurrence and characterization of hypovirulence in the tan sclerotial isolate S10 of Sclerotinia sclerotiorum. Mycol. Res. 107, 1350-1360. doi: 10.1017/s0953756203008591

Li, N., Chen, F., Cui, F., Sun, W., Zhang, J., Qian, L., et al. (2017). Improved postharvest quality and respiratory activity of straw mushroom (Volvariella volvacea) with ultrasound treatment and controlled relative humidity. Sci. Horti. 225, 56-64. doi: 10.1016/j.scienta.2017.06.057

Li, T., Wang, Y., Zhang, J., Zhao, Y., and Liu, H. (2011). Trace element content of Boletus tomentipes mushroom collected from Yunnan. China. Food Chem. 127, 1828-1830. doi: 10.1016/j.foodchem.2011.02.012

Little, G. N., and Gordon, M. A. (1967). Survival of fungus cultures maintained under mineral oil for twelve years. Mycologia 59, 733-736.

Liu, Q., Zheng, L., He, F., Zhao, F., Shen, Z., and Zheng, L. (2015). Transcriptional and physiological analyses identify a regulatory role for hydrogen peroxide in the lignin biosynthesis of copper-stressed rice roots. Plant Soil 387, 323-336. doi: 10.1007/s11104-014-2290-7

Liu, Z., Zhang, K., Lin, J. F., and Guo, L. Q. (2011). Breeding cold tolerance strain by chemical mutagenesis in Volvariella volvacea. Sci. Horti. 130, 18-24. doi: 10.1016/j.scienta.2011.06.020

Magae, Y., Akahane, K., Nakamura, K., and Tsunoda, S. (2005). Simple colorimetric method for detecting degenerate strains of the cultivated basidiomycete Flammulina velutipes (Enokitake). Appl. Environ. Microb. 71, 6388-6389. doi: 10.1128/aem.71.10.6388-6389.2005

Magae, Y., and Hayashi, N. (1999). Double-stranded RNA and virus-like particles in the edible basidiomycete Flammulina velutipes (Enokitake). Fems. Microbiol. Lett. 180, 331-335. doi: 10.1016/s0378-1097(99)00503-0

Maijala, P., Fagerstedt, K., and Raudaskoski, M. (1991). Detection of extracellular cellulolytic and proteolytic activity in ectomycorrhizal fungi and Heterobasidion annosum (Fr.) Bref. New Phytol. 117, 643-648. doi: 10.1111/j.1469-8137.1991. tb00968.x
Mata, G., and Savoie, J. M. (1998). Extracellular enzyme activities in six Lentinula edodes strains during cultivation in wheat straw. World. J. Microb. Biot. 14, 513-519.

Mathew, J., Smina, T. P., and Janardhanan, K. K. (2008). Antioxidant and antitumor activities of cultured mycelium of culinary-medicinal paddy straw mushroom Volvariella volvacea (Bull.: Fr.) Singer (Agaricomycetideae). Int. J. Med. Mushrooms. 10, 139-147. doi: 10.1615/intjmedmushr.v10.i2.40

Meng, L., Fu, Y., Li, D., Sun, X., Chen, Y., Li, X., et al. (2019). Effects of corn stalk cultivation substrate on the growth of the slippery mushroom (Pholiota microspora). RSC Adv. 9, 5347-5353. doi: 10.1039/C8RA10627D

Mihai, C. M., Mãrghitaş, L. A., Dezmirean, D. S., Chirilã, F., Moritz, R. F., and Schlüns, H. (2012). Interactions among flavonoids of propolis affect antibacterial activity against the honeybee pathogen Paenibacillus larvae. J. Invertebr. Pathol. 110, 68-72. doi: 10.1016/j.jip.2012.02.009

Ozsoy, N., Can, A., Yanardag, R., and Akev, N. (2008). Antioxidant activity of Smilax excelsa L. leaf extracts. Food. Chem. 110, 571-583. doi: 10.1016/j. foodchem.2008.02.037

Palacio, A., Gutiérrez, Y., Rojas, D., Atehortúa, L., and Zapata, P. (2017). Viability of Basidiomycete fungal strains under different conservation methods: cryopreservation vs. freeze-drying processes. Actu. Biol. 36, 13-21.

Rai, M., Tidke, G., and Wasser, S. P. (2005). Therapeutic potential of mushrooms. Nat. Prod. Radiance 4, 246-257.

Rajauria, G., Jaiswal, A. K., Abu-Ghannam, N., and Gupta, S. (2010). Effect of hydrothermal processing on colour, antioxidant and free radical scavenging capacities of edible Irish brown seaweeds. Int J. Food Sci. Tech 45, 2485-2493. doi: 10.1111/j.1365-2621.2010.02449.x

Santos, T., Connolly, C., and Murphy, R. (2015). Trace element inhibition of phytase activity. Biol. Trace Elem. Res. 163, 255-265. doi: 10.1007/s12011-0140161-y

Sermkiattipong, N., and Charoen, S. (2014). Development of straw mushroom strain for high yield by gamma radiation. Int. J. Agric. Technol. 5, 1051-1064.

Shen, H. Y., De, S. S., Moonjai, N., Verstrepen, K. J., Delvaux, F., and Delvaux, F. R. (2004). Effects of CO2 on the formation of flavour volatiles during fermentation with immobilised brewer's yeast. Appl. Microbiol. Biot. 64, 636-643. doi: 10. 1007/s00253-003-1523-0

Sun, S., Deng, C., Zhang, L., and Hu, K. (2017). Molecular analysis and biochemical characteristics of degenerated strains of Cordyceps militaris. Arch. Microbiol. 199, 939-944. doi: 10.1007/s00203-017-1359-0

Sun, X., Huang, W., Xiao, S., Liang, C., Zhang, S., Liu, Z., et al. (2014). Extracellular expression and efficient purification of a functional recombinant Volvariella volvacea immunomodulatory protein (FIP-vvo) using pichia pastoris system. Protein. Expres. Purif. 94, 95-100. doi: 10.1016/j.pep.2013.10.022

Tarkka, M. T., Schrey, S., and Nehls, U. (2006). The alpha-tubulin gene AmTuba1: a marker for rapid mycelial growth in the ectomycorrhizal Basidiomycete Amanita muscaria. Curr. Genet. 49, 294-301. doi: 10.1007/s00294-006-0056-3

Voyron, S., Roussel, S., Munaut, F., Varese, G. C., Ginepro, M., Declerck, S., et al. (2009). Vitality and genetic fidelity of white-rot fungi mycelia following different methods of preservation. Mycol. Res. 113, 1027-1038. doi: 10.1016/j. mycres.2009.06.006

Wang, C., Butt, T. M., and St Leger, R. J. (2005). Colony sectorization of Metarhizium anisopliae is a sign of ageing. Microbiology 151, 3223-3236. doi: 10.1099/mic.0.28148-0

Wang, J., Guo, L., and Lin, J. (2009). Composition of transgenic Volvariella volvacea tolerant to cold stress is equivalent to that of conventional control. J. Agr. Food Chem. 57, 2392-2396. doi: 10.1021/jf803363g

Wu, J. Y., Chen, C. H., Chang, W. H., Chung, K. T., Liu, Y. W., Lu, F. J., et al. (2011). Anti-cancer effects of protein extracts from calvatia lilacina, pleurotus ostreatus and Volvariella volvacea. Evid. Based. Complemen. Alternat. Med. 2011:982368. doi: 10.1093/ecam/neq057

Yin, J., Xin, X., Weng, Y., and Gui, Z. (2017). Transcriptome-wide analysis reveals the progress of Cordyceps militaris subculture degeneration. Plos One 12:e0186279. doi: 10.1371/journal.pone.0186279

Zhang, Z., Cao, H., Chen, C., Chen, X., Wei, Q., and Zhao, F. (2017). Effects of fermentation by Ganoderma lucidum and Saccharomyces cerevisiae on rape pollen morphology and its wall. J. Food Sci. Tech. 54, 4026-4034. doi: 10.1007/ s13197-017-2868-1

Zhao, F. Y., Lin, J. F., Zeng, X. L., Guo, L. Q., Wang, Y. H., and You, L. R. (2010). Improvement in fruiting body yield by introduction of 
the Ampullaria crossean multi-functional cellulase gene into Volvariella volvacea. Bioresour. Technol. 101, 6482-6486. doi: 10.1016/j.biortech.2010. 03.035

Zhao, J., Liu, W., Chen, D., Zhou, C., Song, Y., Zhang, Y., et al. (2015). Microbiological and physicochemical analysis of pumpkin juice fermentation by the Basidiomycetous Fungus Ganoderma lucidum. J. Food. Sci. 80, 241-251. doi: $10.1111 / 1750-3841.12741$

Zhou, H., Bi, P., Wu, X., Huang, F., and Yang, H. (2014). Improved polysaccharide production in submerged culture of ganoderma lucidum by the addition of coixenolide. Appl. Biochem. Biotech. 172, 1497-1505. doi: 10.1007/s12010-0130623-2
Conflict of Interest Statement: The authors declare that the research was conducted in the absence of any commercial or financial relationships that could be construed as a potential conflict of interest.

Copyright $\odot 2019$ Chen, Zhang, Liu, Cui, Miao, Cheng and Zhao. This is an openaccess article distributed under the terms of the Creative Commons Attribution License (CC BY). The use, distribution or reproduction in other forums is permitted, provided the original author(s) and the copyright owner(s) are credited and that the original publication in this journal is cited, in accordance with accepted academic practice. No use, distribution or reproduction is permitted which does not comply with these terms. 